\title{
GRADES OF GALLBLADDER DISEASES USING THE GALLBLADDER CONTRACTION INDEX: A PILOT STUDY
}

\author{
* A. C. UGWU ${ }^{1}$, A. N. ETEUDO ${ }^{2}$, C. O. NJOKU ${ }^{2}$ \\ 1.Department of Radiology, Federal Medical Center, Abakaliki, Ebonyi state, Nigeria. \\ 2. Department of Anatomy, Ebonyi State University, Ebonyi State. \\ (*Corresponding author, +2348076241297, tonybullng@yahoo.ca)
}

\begin{abstract}
Summary: The aim of this study was to develop a pilot model for the assessment of the severity of gallbladder diseases based on gallbladder contraction index, clinical and sonographic appearances of the gallbladder. The gallbladder contraction index (GBCI) was obtained as the average of the first ten and the first 20 minutes contraction indices. A range of 5\% to $77 \%$ previously obtained in normal subjects was adopted in this study. Gallbladder contraction index in combination with other variables: sonographic appearances and clinical presentations were used for the grading of gallbladder diseases in the present study. This pilot model may have a good diagnostic performance but a clinical prospective evaluation is needed to confirm its actual value.
\end{abstract}

Key Words: Milk ultrasonography, gallbladder contraction index, gallbladder disease.

\section{Introduction}

Milk Ultrasonography (MU) is a cholecystodynamic study whereby gallbladder emptying or refilling is assessed by ingestion of milk. Some of the peptides (hormones) for example, cholecystokinin, gastrin, neurotesin, somatostatin, vasoactive intestinal polypeptide, substance $\mathrm{P}$, bombesin, and the endomorphins, have been demonstrated to occur in the brain (Long et al, 1984). CCK is present in both the brain and gut and is therefore a neuropeptide, possibly with a neurotransmitter role, as well as a hormone. In the gut the highest tissue concentrations are in the upper small intestine but it can be detected in the ileum. CCK is present in both the mucosa and the muscle of the intestine. In the mucosa it is present in the endocrine cell (Long, et al, 1984).

Motility disorders occur when a physiological pattern of motility is disrupted, or absent or replaced by an aberrant pattern (Wingate, 1984). Hence, the mathematical analysis of minute- by- minute ultrasonography measurements of gallbladder volume variations yields both physiological and pathological insight (Pallota, 2003) Clinicians have in their diagnostic armamentarium a wide range of techniques for the preoperative evaluation of gallbladder, such as physical examination, biochemical examination, gray and colour
Doppler ultrasonography, axial computed tomography, scintigraphy and magnetic resonance imaging. Several studies have used ultrasonography to evaluate gallbladder contraction index, GBCI (Ugwu, et al, 2007,Ugwu ${ }^{\mathrm{a}} ; 2006$, Pons et al, 2003, Siegel et al,2000, Cay et al, 2006, Acalovschi et al, 2004, Guliter, et al, 2003), but none has come up with a grading pattern for gallbladder diseases. Meanwhile no model for grading has been proposed to assist in the determination of the severity of gallbladder disease, prognosis and treatment algorithm.

In the present study, we aimed to develop a model to be used in the grading of gallbladder diseases.

\section{Materials and Methods}

This was a prospective study. Fifty normal, apparently healthy adult Nigerians, with no history of hepatobiliary disease or any other disease known to affect gallbladder motility were studied $\left(\mathrm{Ugwu}^{\mathrm{b}} ; 2006\right)$. The GBCI ranged from $5 \%$ to $77 \%$ in normal subjects $\left(\mathrm{Ugwu}^{\mathrm{b}}\right.$; 2006). Hence a benchmark of $5 \%$ was used for the formulative design.

Five subjects with history of gallbladder diseases were assessed in this pilot study. Approval for the study was given by Jeomedic ultrasound center Research Board, Abakaliki, 
Ebonyi State, according to the Helsinki Declaration (1996). Informed consent was obtained from each subject. Subjects were advised to report to the department in the morning having fasted overnight and without breaking fast. Three serial ultrasound scans were carried out on each subject as follows:

(a) Before drinking a tin of full cream milk (165mls). Trade name-

Three crowns (Frieshland Foods, WAMCO, Lagos, Nigeria)

(b) 10 minutes postprandial;

(c) 20minutes postprandial.

These procedures were used to assess the variations of gallbladder prolate ellipsoid volume with bile emptying (contraction). Ultrasound studies were performed using sono line SL-1 (siemens medical systems, U.S.A Inc, Ultrasound group Issaquah (WA) with a sector transducer of $3.5 \mathrm{MH}_{\mathrm{Z}}$ frequency. The skin of the right upper quadrant was covered with ultrasound gel and the probe applied to it. After visualization of the maximal gallbladder longitudinal outline, the length and maximal

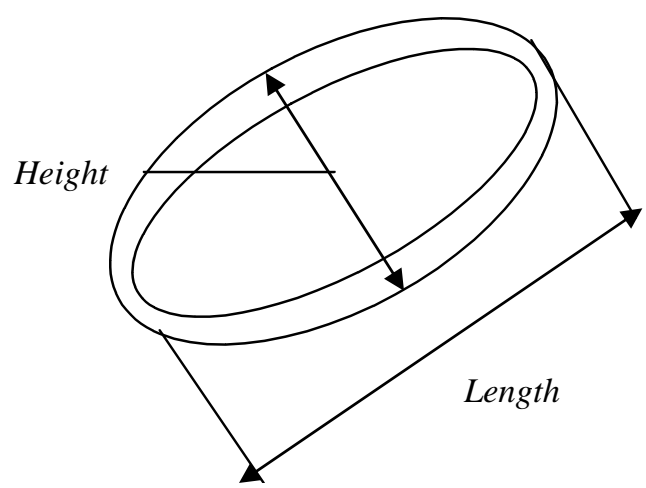

Fig 1 A line drawing showing a longitudinal section of the gallbladder. anteroposterior diameter (height) were measured on arrested respiration either in supine or oblique position (fig 1). Thereafter, the probe was turned through $90^{\circ}$ (fig 2) to obtain the maximal coronal diameter (width). The electronic calipers cross one another at $90^{\circ}$ to make 3-othorgonal plane measurements. The 3 measurements were repeated 10 minutes and 20 minutes postprandial. Gallbladder volume was obtained using the volume calculation for the prolate ellipsoid (length $\mathrm{x}$ width $\mathrm{x}$ height $\mathrm{x}$ 0.523) (Ho, et al, 1998). Gallbladder contraction index (GBCI) is the percentage decrement of postprandial size (volume) from the initial size (Ho et al, 1998). The $10^{\text {th }}$ minute GBCI and the $20^{\text {th }}$ minute GBCI were computed for each subject and the average of two used as the actual (GBCI.)

Cholecystodynamic Analysis

Descriptive Statistical technique was used. The gallbladder contraction indices were expressed as percentages and graded as shown in the table 2 .

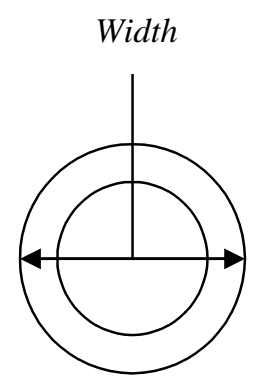

Fig 2: A line drawing showing a transverse section of the gallbladder.

\section{Results}

Table 1. Model Development

\begin{tabular}{lccc}
\hline STAGES & GBCI & $\begin{array}{l}\text { CLINICAL } \\
\text { EVIDENCE }\end{array}$ & $\begin{array}{l}\text { SONOGRAPHY } \\
\text { EVIDENCE }\end{array}$ \\
\hline 1 & $<5 \%$ & + & + \\
$2 \mathrm{~A}$ & $<5 \%$ & - & + \\
$2 \mathrm{~B}$ & $<5 \%$ & + & - \\
$2 \mathrm{C}$ & $>5 \%$ & + & + \\
$3 \mathrm{~A}$ & $>5 \%$ & - & + \\
$3 \mathrm{~B}$ & $>5 \%$ & + & - \\
$3 \mathrm{C}$ & $<5 \%$ & - & - \\
\hline
\end{tabular}

GBCI=Gallbladder Contraction Index

$(+)=$ Presence of Clinical / Sonographic Evidence

$(-)=$ Absence of Clinical / Sonographic Evidence 
Table 2 shows gallbladder contraction indices in some patients with positive histories of gallbladder diseases

Table 2: Gallbladder contraction indices in patients with positive history of gallbladder diseases

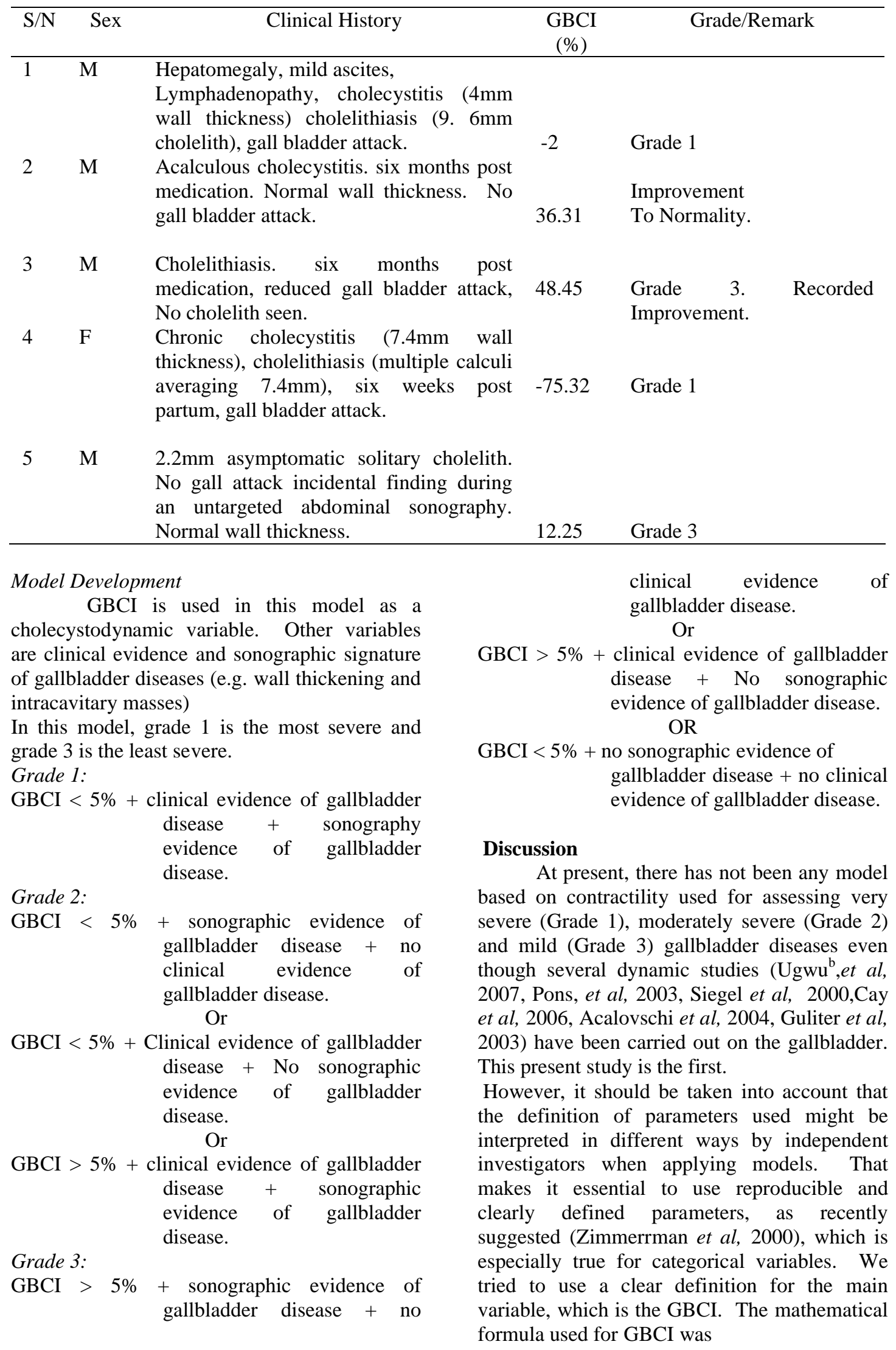


$\frac{(\mathrm{V} 1-\mathrm{V} 2)}{\mathrm{V} 1} \times \frac{100}{1}$

where V1 is the Initial Gallbladder Volume V2 is the Postprandial Gallbladder Volume This model is a mathematical formula, and clinicians may be reluctant to use it. Actually, it is simple to use. Only a computer or even simply a hand calculator is needed. Once all the parameters to be used in the model are obtained in the evaluation of a given gallbladder in fasting and postprandial phases, their values (measurements) are applied to the model's mathematical formula, and result will allow the estimation of the severity of the disease. A possible limitation of this proposed model is the use of two-dimensional ultrasound to determine gallbladder volume and contraction index, which has been shown to have significant problem when compared with gold standard (dynamic scintigraphy). Further studies in this field apart from being carried out on a larger samples of both normal subjects and patients with gallbladder diseases to give high power (enough sample size) would need to be compared with crossover studies using gold standards. In this case, the gold standards would be dynamic cholescintigraphy (DCS) and possibly surgical pathology. The use of dynamic ultrasonography (DUS) may have contributed to the wide variability in the percentages $\left(\mathrm{Ugwu}^{\mathrm{b}}\right.$, 2006) used to identify normal gallbladder function $(5 \%-77 \%)$ in this paper. This could obviously be due to the use of ellipsoid formula in volume determination for various gallbladder shapes and contours.

Finally, we propose this model for predicting gallbladder disease severity and affirm that the prospective evaluation of this model in large series of subjects in different racial and socio-cultural background would further determine its actual value.

\section{References}

Acalovschi, M., Dumitracu, D. L., Nicoara, C. D. (2004). Gallbladder contractility in liver cirrhosis: Comparative study in patients with and without gallbladder stones. Dig. Dis. Sci. 49(1):17-24.

Cay, A., Imamoglu, M., Sarihan, H. (2006). Ultrasonographic evaluation of fatty meal stimulated gallbladder contraction in the diagnosis of biliary dyskinesia in children. Acta. Paediatr. 95(7):838-842.
Contractility in term and preterm neonates: Normal values and clinical application in ultrasonography. Acta. Paediatr. 87(7): 799-804.

Guliter, S., Yilmaz, S., Karakan, T. (2003). Evaluation of gallbladder volume and motility in non-insulin-dependent diabetes mellitus patients using real time ultrasonography. J. Clin Gastroenterol. 37(4):288-291.

Ho, M. L., Chen, J. Y., Ling up, S. U. P. H.. (1998). Gallbladder volume and Ledingham JGG, Warrel DA (eds). Oxford textbook of medicine, Vol1, London: Oxford University press; P12.33335.

Long, R. G., Polak, J. M., Bloom, S. R.. (1984). Hormones and the GIT In: weatherall DL, Ledingham JGG, Warrel DA(eds). Oxford Textbook of medicine, vol1, London: oxford University press; P12.47.

Pallota, N. (2003). Ultrasonography in the assessment of gallbladder motor activity. Dig Liver Dis. Jul; 35 suppl. 3:67-69.

Pons, V., Ballesta, A., Ponce, M. (2003). Dynamic ultrasonography in the diagnosis of gallbladder dysfunction: reliability of a simple method with easy clinical application. Gastroenterol. Hepatol. 26(1): 8-12.

Siegel, A., Kuhn, J. C., Crow, H. (2000). Gallbladder ejection fraction: correlation of scintigraphic and ultrasonographic techniques. Clin. Nucl. Med. 25(1):1-6.

Ugwu, A. C. ${ }^{\text {a }}$ (2006). Cholecystodynamic: A new simple regression formula. Pak. J. Med. Res. 45(1):17-20.

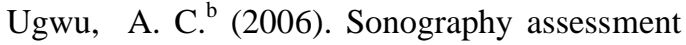
of gallbladder sizes and contraction index in adult Nigerian population; Completed MSc dissertation.

Wingate, D. L. (1984). Disorders of motility. In: Weatherrall DL,

Zimmerrman, D., Valetin, L., Borne, T. H., Collins, W. P., Verrelst, H., Vergote, I. (2000). Terms, definitions and measurements to describe the sonographic features of adnexal tumors: a consensus from international ovarian tumor Analysis (IOTA) group. Ultrasound. Obstet. Gynecol. 16:500-505.

Received: $24 / 7 / 2007$

Accepted: 5/11/2007 